\title{
Clinical Manifestations of Respiratory Bronchiolitis as an Incidental Finding in Surgical Lung Biopsies: A Retrospective Analysis of a Large Austrian Registry
}

\author{
Stefan J. Scheidla ${ }^{\mathrm{a}}$ Marlene Kusej $^{\mathrm{a}}$ Holger Flick $^{\mathrm{a}}$ Elvira Stacher ${ }^{\mathrm{b}}$ \\ Veronika Matzic Gabor Kovacsa, d Helmut H. Popper ${ }^{b} \quad$ Ulrich Costabel $^{\mathrm{e}}$ \\ Horst Olschewski ${ }^{a}$ \\ a Division of Pulmonology, Department of Internal Medicine, ${ }^{\mathrm{b}}$ Institute of Pathology, ' Department of Thoracic \\ Surgery, and d Ludwig Bolzmann Institute of Lung Vascular Research, Medical University of Graz, Graz, Austria; \\ e Interstitial and Rare Lung Disease Unit, Ruhrlandklinik, Universitiy of Duisburg-Essen, Essen, Germany
}

\section{Key Words}

Alveolar macrophages · Lung biopsy - Respiratory bronchiolitis · Lung cancer · Histiocytosis · Interstitial lung disease

\begin{abstract}
Background: While respiratory bronchiolitis (RB) is a frequent histopathological finding in smoker's lungs, RB-associated interstitial lung disease (RB-ILD) remains a rare disease. Objectives: We analyzed how the histological finding of RB was associated with clinical information in a series of 684 consecutive surgical lung biopsies. Methods: Retrospective analysis with delineation of clinical manifestations, smoking habits, pulmonary function test, and blood gas analysis in patients with RB in surgical lung biopsy. In 240 of these biopsies, RB was diagnosed, and in 146 of these cases a full clinical dataset was available. Results: The final diagnosis of these 146 patients was consistent with RB-ILD $(n=18)$, pulmonary Langerhans cell histiocytosis ( $n=7)$, various ILD $(n=9)$, spontaneous pneumothorax $(n=43)$, traumatic pneumothorax $(n=5)$, lung cancer $(n=41)$, various benign lung tumors $(n=8)$, and chronic pulmonary effusion $(n=15)$. Smoking history was positive in $93 \%$ of patients, $72 \%$ re-
\end{abstract}

vealed centrilobular emphysema in their biopsy, and 58\% described dyspnea as the main symptom. Amongst these diagnoses there were significant differences in age and smoking habits, but only small distinctions in pulmonary function test and blood gas analysis. Out of the patients with RB-ILD, $17 \%$ developed lung cancer in the later course. Conclusion: $\mathrm{RB}$ is strongly related to smoking, emphysema, and dyspnea and frequently associated with lung cancer. RB-ILD is a rare disease that may represent a considerable risk for lung cancer. Pulmonary function testing and blood gas analysis do not differ between RB-associated diseases. The finding of RB should prompt further diagnostic workup, and in case of RBILD, entail regular screening for lung cancer.

(c) 2015 S. Karger AG, Basel

\section{Introduction}

Respiratory bronchiolitis (RB), first described in 1974 [1], is a well-recognized histopathological pattern which was initially considered to be 'of little clinical significance'. It is characterized by the accumulation of pigmented macrophages within the respiratory bronchioles and adjacent alveoli [2]. Considered to be the anatomic correlate of

\section{KARGER}

E-Mail karger@karger.com

www.karger.com/res
C 2015 S. Karger AG, Basel

$0025-7931 / 15 / 0911-0026 \$ 39.50 / 0$
Dr. Stefan J. Scheidl

Klinische Abteilung für Lungenkrankheiten der Medizinischen Universitätsklinik Graz

Auenbruggerplatz 20, AT-8047 Graz (Austria)

E-Mail stefan.scheidl@medunigraz.at 
small airways disease in cigarette smokers [3], RB is commonly referred to as 'smokers' bronchiolitis' [4]. Almost exclusively in heavy cigarette smokers, the extent of alveolar accumulation and bronchiolar inflammation extends to the peribronchiolar interstitium, and it may be severe enough to cause clinical, physiological, and imaging features of interstitial lung disease (ILD). When other distinct ILD are ruled out, this clinicopathological entity is called RB-associated ILD (RB-ILD) [5]. Whether RB and RB-ILD can be separated by histopathological criteria has been subject of discussion [5-11]. Most probably essential histological features of RB-ILD are indistinguishable from smoking-related RB, hence diagnosis of RB-ILD is de facto clinical, requiring the presence of a variable combination of clinical signs and symptoms, pulmonary function test abnormalities, and typical findings on chest radiography or high-resolution computed tomography (HR-CT) [12-14]. The histological pattern of RB is seen in a variety of lung diseases [15], including pulmonary Langerhans cell histiocytosis (PLCH) [16, 17], pneumothorax [18], or lung cancer (LC) [19], but is often underrated as an incidental finding on lung biopsy specimens. It is not clear whether the histological pattern of RB is predisposing to other more severe lung diseases [20]. Patients with RB or RB-ILD may develop LC [21, 22], and patients with PLCH nearly always have RB and frequently develop pneumothorax [23]. Pneumothorax in PLCH is most often related to scarring. In RB-ILD, pneumothorax is less common. The clinical relevance and the association of RB with other smoking-related lung diseases have not been investigated on the basis of a large series of surgical lung biopsies. To our knowledge, this is the first study to analyze a large cohort of patients with histologically proven $\mathrm{RB}$ and define disease-specific subgroups as well as possible risk factors for associated diseases. To date, there are only a few case series, case reports, and reviews on clinical manifestations of RB-ILD, and conclusions are based on limited and heterogeneously defined outcome measures. Our aim was to describe the clinical and laboratory features that are associated conditions in a cohort of patients with a histological pattern of RB.

\section{Materials and Methods}

Between 1998 and 2009, histological specimens of 684 consecutive patients were obtained via open lung biopsy or video-assisted lung biopsy for diagnostic reasons. Surgical intervention was performed for routine diagnostic workup of pulmonary tissue in diffuse parenchymal lung disease (DPLD; $n=69 ; 10 \%$ ), pneumotho$\operatorname{rax}(\mathrm{n}=101 ; 15 \%)$, lung tumors including nodular lesions and hilar lymphadenopathy ( $\mathrm{n}=463 ; 68 \%)$, and miscellaneous causes ( $\mathrm{n}=$ $51 ; 7 \%$ ). The diagnosis of RB was made in 240 of these histological specimens, including 54 cases of DPLD, 74 cases of pneumothorax, 74 cases of LC, and 38 cases of miscellaneous causes. A full dataset, including smoking habits, lung function test (LFT), blood gas analysis, chest X-ray, and HR-CT prior to surgery, was available in 146 patients, including 34 patients with DPLD, 48 patients with pneumothorax, 49 patients with LC, and 15 patients with miscellaneous causes. We retrospectively reviewed these cases in the files of the Medical University of Graz. Of the 146 patients, 109 (75\%) were assigned to 4 distinct groups: (1) RB-ILD $(n=18)$ - the diagnosis of RB-ILD was made when HR-CT scans of the lung suggested presence of ILD, histological criteria for RB were met, and other distinct DPLD had been ruled out, (2) RB associated with PLCH (RBPLCH; $n=7)$, (3) RB associated with spontaneous pneumothorax $($ RB-SP; $\mathrm{n}=43)$, and $(4)$ RB associated with LC (RB-LC) $(\mathrm{n}=41)$. We describe clinical manifestations, smoking habits, pulmonary function test, and blood gas analysis and compare anthropometrics and functional data of these 4 major patient groups. The remaining 37 patients were not eligible for statistical analysis due to their heterogeneity (fig. 1). The study was approved by the Ethics Committee of the Medical University of Graz (EK No.: 21-377 ex 09/10).

\section{LFT and Blood Gas Analysis}

Forced expiratory 1 -second volume $\left(\mathrm{FEV}_{1}\right)$, forced vital capacity $(\mathrm{FVC})$, ratio of $\mathrm{FEV}_{1}$ to $\mathrm{FVC}\left(\mathrm{FEV}_{1} / \mathrm{FVC}\right)$, maximal expiratory flow at $50 \%$ of FVC (MEF50), maximal expiratory flow at $25 \%$ of FVC (MEF25), total lung capacity, residual volume, and airway resistance were determined by standard procedures. All measurements conformed to the guidelines of the European Community for Steel and Coal, and for each individual values were expressed as percentage of predicted values. Blood gas analysis was sampled from arterialized capillary blood at rest with determination of arterial oxygen $\left(\mathrm{paO}_{2}\right)$ and carbon dioxide partial pressure $\left(\mathrm{paCO}_{2}\right)$, oxygen saturation $\left(\mathrm{O}_{2}\right.$-Sat), and alveolar-arterial oxygen gradient $\left(\mathrm{AaDO}_{2}\right)$.

\section{Radiological Features}

For the diagnosis of RB-ILD, HR-CT scans of the lung were evaluated for ground glass opacities, central and/or peripheral wall thickening, centrilobular nodules, centrilobular emphysema, reticulation of the lower lungs, patchy areas of hypoattenuation, and honeycombing.

\section{Histopathological Specimens}

Hematoxylin and eosin-stained sections of formalin-fixed and paraffin-embedded sections were examined. The diagnosis of RB was made when abundant pigment-laden macrophages (smokers' macrophages) in patchy distribution were present in the lumen of respiratory bronchioles both with extension into the centrilobular lumen of alveolar spaces. The characteristic appearance is shown in figure 2 .

\section{Statistics}

Data were analyzed using the SPSS statistical package (SPSS version 18.0; SPSS Inc., Chicago, Ill., USA). The groups were tested for statistical significance using Kruskal-Wallis ANOVA. We employed the Mann-Whitney-Wilcoxon test for comparison of 2 patient groups. Bonferroni correction was applied where multiple testing was performed. Data are given as mean \pm SD. $p$ values $<0.05$ were considered significant. 


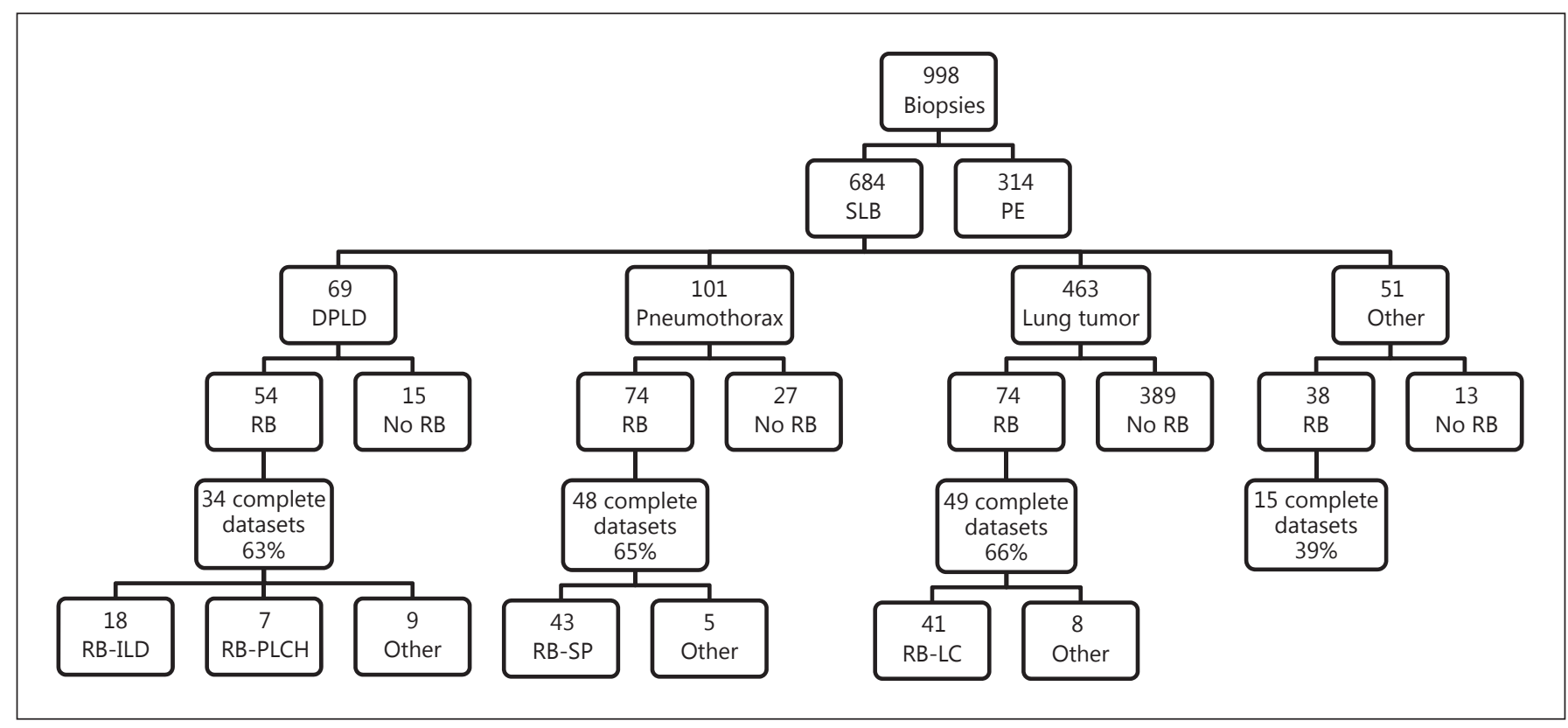

Fig. 1. Distribution of disease entities found in association with RB. SLB = Surgical lung biopsy; PE = probe excision (via bronchoscopy or CT-guided needle aspiration).
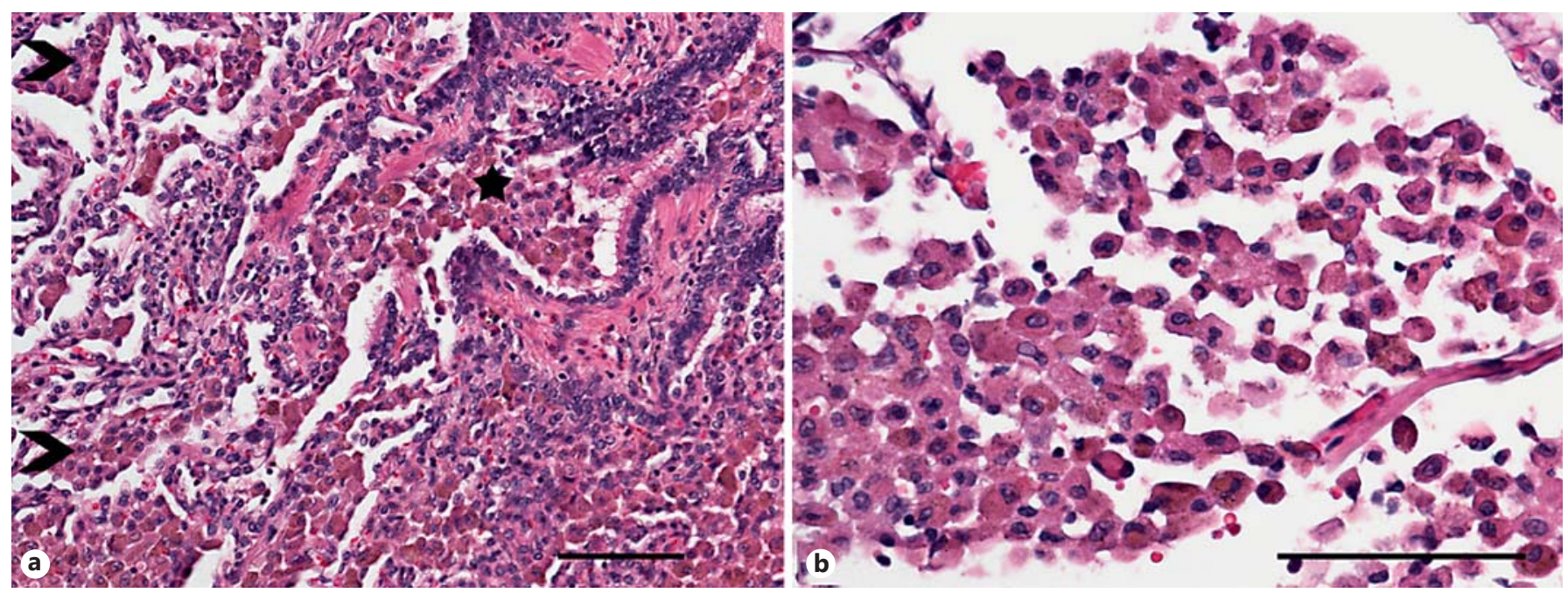

Fig. 2. Histological findings in RB. a Macrophages in abundance in a respiratory bronchiolus (asterisk) and neighboring alveolar spaces (arrowheads). b Macrophages with typical brownish pigmentation. Hematoxylin and eosin staining. Scale bar $=100 \mu \mathrm{m}$.

\section{Results}

Of 240 patients with RB, 146 patients were eligible for further analysis. Of these 146 patients, 135 had a definitive smoking history (93\%). In 7 cases, the smoking status was not available (1 female patient with PLCH, 1 female patient with 'other' DPLD, and 5 male patients with SP), and 4 patients were definitive never-smokers (2 male patients with 'other' DPLD, 1 female patient with 'other' lung tumor, and 1 female patient with 'miscellaneous
28

Respiration 2016;91:26-33 DOI: $10.1159 / 000442053$
Scheidl/Kusej/Flick/Stacher/Matzi/ Kovacs/Popper/Costabel/Olschewski 
Table 1. Distribution, anthropometric data, and smoking habits of patients with 'major' disease entities found in association with $\mathrm{RB}$

\begin{tabular}{|c|c|c|c|c|}
\hline Distribution/anthropometrics & Diagnosis & $\mathrm{M}: \mathrm{F}$ & Age, years & Pack years \\
\hline All RB (n = 146) & & 101:45 & $45 \pm 16$ & $31 \pm 26$ \\
\hline \multirow[t]{3}{*}{$\mathrm{DPLD}+\mathrm{RB}(\mathrm{n}=34)$} & RB-ILD (n = 18) & $13: 5$ & $48 \pm 11$ & $30 \pm 26$ \\
\hline & $\mathrm{PLCH}(\mathrm{n}=7)$ & $4: 3$ & $38 \pm 10$ & $29 \pm 29$ \\
\hline & Other $(\mathrm{n}=9)$ & $6: 3$ & $49 \pm 4$ & $19 \pm 12$ \\
\hline \multirow[t]{2}{*}{ Pneumothorax + RB $(n=48)$} & Spontaneous $(n=43)$ & $29: 14$ & $31 \pm 11$ & $14 \pm 8$ \\
\hline & Traumatic $(\mathrm{n}=5)$ & $5: 0$ & $29 \pm 9$ & $19 \pm 17$ \\
\hline \multirow[t]{2}{*}{ Lung tumor + RB $(\mathrm{n}=49)$} & $\mathrm{LC}(\mathrm{n}=41)$ & $26: 15$ & $60 \pm 9$ & $47 \pm 30$ \\
\hline & Other $(\mathrm{n}=8)$ & $4: 4$ & $47 \pm 9$ & $28 \pm 11$ \\
\hline Miscellaneous + RB $(n=15)$ & Miscellaneous $(\mathrm{n}=15)$ & $11: 4$ & $49 \pm 15$ & $31 \pm 19$ \\
\hline
\end{tabular}

Age and smoking habits are given as means \pm SD.

Table 2. LFT and blood gas analysis of patients with RB and associated diseases

\begin{tabular}{|c|c|c|c|c|}
\hline LFT and BGA & $\begin{array}{l}\text { RB-ILD } \\
(\mathrm{n}=18)\end{array}$ & $\begin{array}{l}\text { RB-SP } \\
(n=43)\end{array}$ & $\begin{array}{l}\text { RB-LC } \\
(\mathrm{n}=41)\end{array}$ & $\mathrm{p}$ \\
\hline $\mathrm{FEV}_{1}, \%$ predicted & $68 \pm 17^{a}$ & $81 \pm 17^{\mathrm{a}}$ & $74 \pm 20$ & 0.001 \\
\hline FVC, \% predicted & $73 \pm 20$ & $80 \pm 17$ & $84 \pm 19$ & 0.025 \\
\hline $\mathrm{FEV}_{1} / \mathrm{FVC}, \%$ predicted & $84 \pm 9^{a, b}$ & $89 \pm 10^{\mathrm{a}, \mathrm{c}}$ & $74 \pm 10^{\mathrm{b}, \mathrm{c}}$ & $\leq 0.001$ \\
\hline MEF50, \% predicted & $63 \pm 19^{a}$ & $83 \pm 26^{\mathrm{a}, \mathrm{c}}$ & $53 \pm 32^{c}$ & $\leq 0.001$ \\
\hline MEF25, \% predicted & $51 \pm 27^{\mathrm{a}}$ & $82 \pm 27^{\mathrm{a}, \mathrm{c}}$ & $44 \pm 21^{\mathrm{c}}$ & $\leq 0.001$ \\
\hline TLC, $\%$ predicted & $80 \pm 21^{b}$ & $88 \pm 13^{c}$ & $105 \pm 26^{b, c}$ & 0.002 \\
\hline $\mathrm{RV}, \%$ predicted & $101 \pm 37^{\mathrm{b}}$ & $108 \pm 35^{c}$ & $143 \pm 49^{b, c}$ & 0.002 \\
\hline Rtot, $\mathrm{kPa} \times \mathrm{s} / \mathrm{l}$ & $0.19 \pm 0.15^{\mathrm{b}}$ & $0.16 \pm 0.15^{c}$ & $0.30 \pm 0.28^{b, c}$ & $\leq 0.001$ \\
\hline $\mathrm{paO}_{2}, \mathrm{~mm} \mathrm{Hg}$ & $70 \pm 12^{\mathrm{a}}$ & $81 \pm 16^{\mathrm{a}, \mathrm{c}}$ & $75 \pm 9^{c}$ & 0.058 \\
\hline $\mathrm{paCO}_{2}, \mathrm{~mm} \mathrm{Hg}$ & $38 \pm 5$ & $40 \pm 6$ & $39 \pm 5$ & 0.019 \\
\hline $\mathrm{AaDO}_{2}, \mathrm{~mm} \mathrm{Hg}$ & $30 \pm 13^{a}$ & $20 \pm 9^{a}$ & $25 \pm 10$ & 0.023 \\
\hline
\end{tabular}

Values are given as means \pm SD. In patients with RB-SP, data of LFT and BGA were obtained after pulmonary recompensation. In case of RB-ILD and RB-LC, data were obtained from the preoperative investigation closest to diagnosis. $\mathrm{BGA}=$ Blood gas analysis; $\mathrm{TLC}=$ total lung capacity; $\mathrm{RV}=$ residual volume; Rtot = total airway resistance.

p values $<0.05$ were considered significant (Kruskal-Wallis, ANOVA): ${ }^{\text {a }}$ significant difference between RBILD and RB-SP; ${ }^{b}$ significant difference between RB-ILD and RB-LC; ${ }^{c}$ significant difference between RB-SP and RB-LC.

cause'). We assigned 109 patients (75\%) to 4 distinct groups: RB-ILD ( $\mathrm{n}=18)$, RB-PLCH $(\mathrm{n}=7)$, RB-SP $(\mathrm{n}=$ 43 ), and RB-LC ( $\mathrm{n}=41$; including 26 patients with pulmonary adenocarcinoma and 15 patients with squamous cell carcinoma of the lung). When comparing these 4 groups with each other, we found that patients with RBILD were significantly older and had significantly more pack years than patients with RB-SP. On the other hand, patients with RB-ILD were significantly younger and had significantly fewer pack years than patients with RB-LC. For further age comparison, see table 1.

Average LFT of all 146 patients with RB were close to normal with a slight tendency towards obstruction $\left(\mathrm{FEV}_{1}\right.$ $74 \pm 19 \%$, FVC $79 \pm 19 \%$, and $\mathrm{FEV}_{1} / \mathrm{FVC} 81 \pm 12 \%$ ). While patients with RB-SP showed near to normal LFT after recovery, patients with RB-ILD showed a predomi- 
Table 3. Clinical and histological manifestations of patients with RB and associated diseases

\begin{tabular}{lcllll}
\hline & $\begin{array}{l}\text { RB-ILD } \\
(\mathrm{n}=18)\end{array}$ & $\begin{array}{l}\text { RB-PLCH } \\
(\mathrm{n}=7)\end{array}$ & $\begin{array}{l}\text { RB-SP } \\
(\mathrm{n}=43) \\
29: 14\end{array}$ & $\begin{array}{l}\text { RB-LC } \\
(\mathrm{n}=41)\end{array}$ & $\begin{array}{l}\text { Miscellaneous } \\
(\mathrm{n}=3) \\
26: 15\end{array}$ \\
\hline Cough & $13: 5$ & $4: 3$ & $14(33)$ & $21(50)$ & $12(32)$ \\
Sputum & $10(56)$ & $3(43)$ & $2(5)$ & $9(21)$ & $6(14)$ \\
Fever & $8(44)$ & $0(0)$ & $0(0)$ & $3(7)$ & $2(5)$ \\
Dyspnea & $1(6)$ & $0(0)$ & $33(77)$ & $20(48)$ & $18(49)$ \\
Night sweat & $10(56)$ & $4(57)$ & $0(0)$ & $4(10)$ & $3(7)$ \\
Weight loss & $2(11)$ & $0(0)$ & $1(2)$ & $3(7)$ & $0(0)$ \\
Thoracic pain & $1(6)$ & $2(29)$ & $37(86)$ & $15(36)$ & $10(27)$ \\
Emphysema & $4(22)$ & $5(71)$ & $42(98)$ & $33(79)$ & $17(46)$ \\
Pleuritis & $10(56)$ & $4(57)$ & $28(65)$ & $4(10)$ & $11(30)$ \\
\hline
\end{tabular}

Values are given as $\mathrm{n}(\%)$.

nantly restrictive pattern with an additional aspect of small-airways obstruction with a MEF50 of $63 \pm 19 \%$ predicted and a MEF 25 of $51 \pm 27 \%$ predicted. Whereas patients with RB-LC were more obstructive, especially in the smaller airways, with a MEF50 of $53 \pm 32 \%$ predicted and a MEF25 of $44 \pm 21 \%$ predicted, resembling smallairways disease. Patients with RB-ILD showed the lowest $\mathrm{paO}_{2}$, the lowest $\mathrm{paCO}_{2}$, and the highest $\mathrm{AaDO}_{2}$ values in comparison to patients with RB-SP, RB-LC (table 2), and RB-PLCH (data not shown). There were no significant anthropometric, functional, and clinical differences between patients with RB-SP and patients with pneumothorax caused by trauma, and there were no significant differences between patients with relapsing and nonrelapsing pneumothorax.

In the RB-ILD patients, the HR-CT scans revealed 2-6 of the following radiological features, suggesting presence of ILD. In 13 patients (72\%) we found ground glass opacities, in 9 patients (50\%) central and in 8 patients (44\%) peripheral wall thickening, in 9 patients $(50 \%)$ centrilobular nodules, in 8 patients (44\%) centrilobular emphyse$\mathrm{ma}$, in 5 patients $(28 \%)$ reticulation with predominance of the lower lungs, in 4 patients $(22 \%)$ patchy areas of hypoattenuation, and in 2 patients (11\%) honeycombing. Honeycombing was a minor finding in both patients affected.

In terms of clinical manifestations at first presentation, 60 (41\%) of 146 patients reported cough, which was associated with expectorations in 25 cases (17\%). Eightyfive patients (58\%) suffered from dyspnea and 71 patients (48\%) from thoracic pain. Significant differences were only seen between the RB-SP and the RB-ILD group with

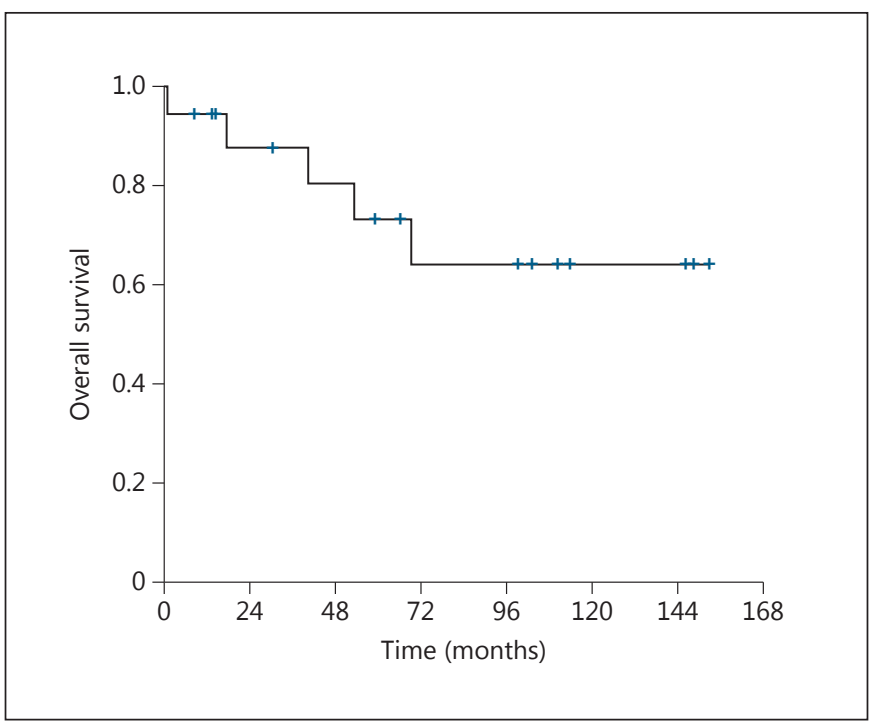

Fig. 3. Kaplan-Meier curve of the overall survival of patients with RB-ILD. During the observation period, 6 patients died and 7 patients were lost to follow-up (blue diamonds, censored). Two patients died due to adenocarcinoma of the lung, 1 patient died due to squamous cell carcinoma, 1 patient died due to pancreas carcinoma, 1 patient died due to cancer of the urinary bladder, and 1 patient died due to liver cirrhosis.

regard to thoracic pain and dyspnea. Based on histological findings, in addition to RB, 106 of the 146 patients (73\%) had a pronounced centrilobular pulmonary emphysema which was most frequently documented in the group of patients with RB-SP (table 3). The male:female ratio of the emphysema patients was 2.5:1 (76:30).
Scheidl/Kusej/Flick/Stacher/Matzi/ Kovacs/Popper/Costabel/Olschewski 
Fig. 4. Hypothesis for the interactions of

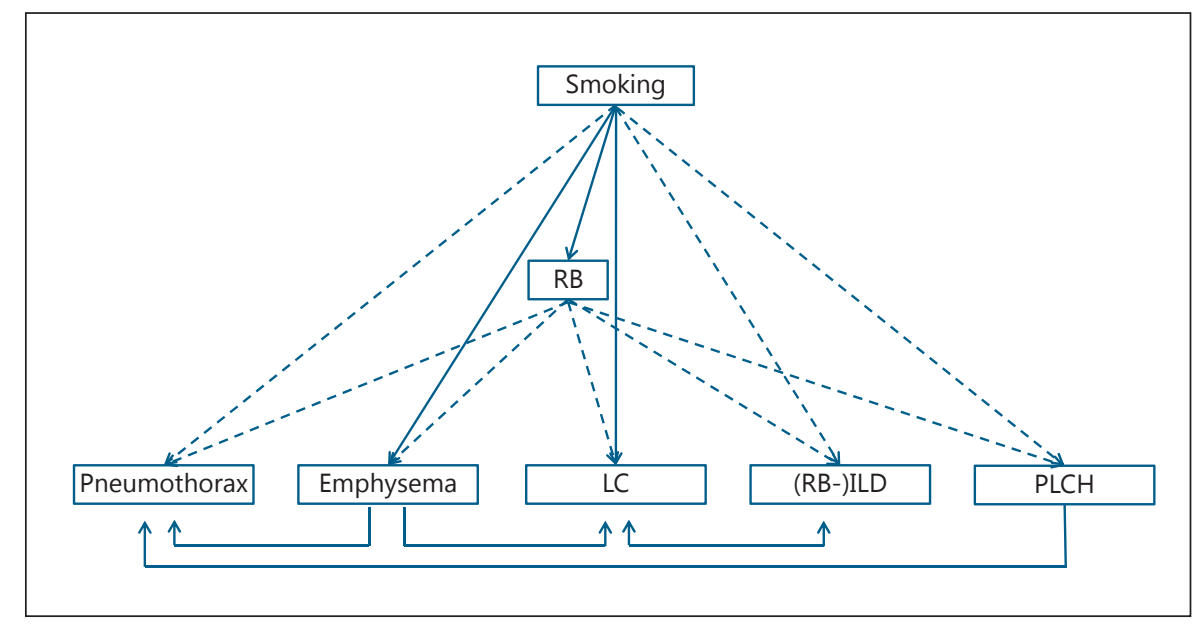

In patients with RB-ILD, long-term survival has not been described in detail. Former studies have suggested a relatively good prognosis. However, the 18 RB-ILD patients identified in our study had no favorable outcome. Six patients (33\%) died within 5 years (fig. 3), 7 patients were lost to follow-up, and 5 patients are still alive. Of the 5 patients alive, 4 patients quit smoking and have since had a stable LFT, 1 patient continues smoking with a significant yearly decline in LFT.

\section{Discussion}

RB-ILD is histologically characterized by an intraluminal and intra-airspace accumulation of finely pigmented macrophages associated with peribronchiolar inflammation and fibrosis [1, 24-26]. Associations between RB and RB-ILD and different lung diseases, such as PLCH, SP, and LC [21, 22, 27], have been reported, and previous studies support the idea that an overlap between different smoking-related diseases is frequent $[12,16,20]$. Our data confirm that RB is nearly always associated with cigarette smoking, and that $\mathrm{RB}$ is strongly associated with centrilobular emphysema, SP, and PLCH which supports the hypothesis that RB may be a prerequisite for SP and $\mathrm{PLCH}$, and that RB, and RB-ILD to some extent, may be a surrogate or forerunner diagnosis pointing to a higher risk of the patient to develop smoke-associated cancer subsequentially (fig. 4). Causes might be similar to those described for LC and pulmonary fibrosis, a disease related to cigarette smoking likewise [28]. Of note, 3 of our patients with RB-ILD (17\%) died of LC in the later course, and 2 patients died of other smoke-related cancers. In the RB-LC group, 26 (63\%) patients had an adenocarcinoma and 15 (37\%) patients had a squamous cell carcinoma. This is in line with a recent report [29], where RB was primarily observed in patients with adenocarcinoma, whereas RB-ILD was associated with peripheral squamous cell carcinoma.

In accordance with previous reports, the overall sex ratio showed a 2:1 male preponderance, with similar proportions in all groups. Within the 4 disease groups, 95\% had a definitive smoking history ranging from 1 to 180 pack years. Our patients with RB and associated diseases demonstrated only slight impairment of their LFT - resembling small-airways disease - and rarely presented with hypoxemia. Due to its subclinical presentation, RB is usually not diagnosed until signs and symptoms of associated pulmonary diseases occur. In the 4 groups of patients with $\mathrm{RB}$, we found small nonsignificant differences in anthropometric data and lung function.

In patients with RB-SP or RB-LC, diagnosis was generally triggered by clinical manifestations of pneumothorax or LC, respectively, and supported by radiological imaging. It is known from the literature that patients with PLCH almost always have RB and frequently develop pneumothorax [23], leading to diagnosis in many cases. In our population, 3 of 7 patients with PLCH had a SP prior to diagnosis. This is in contrast to patients with RBILD, where clinical manifestations are often subtle, X-ray of the chest is not sensitive enough, and surgical lung biopsy may not be able to distinguish RB from RB-ILD. In terms of clinical manifestations, course and outcome of RB-ILD, data are sparse and partially controversial, with only a few case series and reviews reported. The most important clinical manifestations reported in RB-ILD are dry cough, shortness of breath, exertional dyspnea, and 
weight loss, eventually dyspnea at rest and rarely thoracic pain. In our RB-ILD patients, the leading symptoms, sole or combined, were dyspnea (56\%) and, more frequent than in any other disease group, cough (56\%), sputum production (44\%), and night sweats (11\%). Less pronounced symptoms were thoracic pain (22\%) and fever (6\%). Hemoptysis and velcro rales on auscultation were rarely present, and clubbing, reported with an incidence of $12.5-33 \%$ in patients with RB-ILD [21, 30], was only seen in 2 of our cases (11\%).

Pulmonary function testing and blood gas analysis were not helpful to differentiate diseases associated with RB. Patients with RB-ILD and RB-LC showed functional signs of small-airways disease characterized by a marked reduction of the MEF50 and MEF25. Histologically, a predominantly centrilobular emphysema occurred significantly more often in patients with RB-SP and in those with RB-LC, representing the majority of the analyzed patients. Patients with RB-ILD additionally showed a mild restrictive ventilatory pattern, and blood gas analysis demonstrated an augmented $\mathrm{AaDO}_{2}$ and a decrease in $\mathrm{paO}_{2}$ and $\mathrm{paCO}_{2}$ as would be expected in DPLD. Some patients showed combined ventilatory impairment, whereas others presented only with a mild decrease in diffusing capacity of the lung for carbon monoxide. In a few patients, only residual lung volumes were increased, indicating air trapping beyond the obstructed bronchiole, while other patients had a normal pulmonary function test.

Our study has several limitations. The retrospective nature of our study with clinical, physiological, radiological, and gas exchange data, which were not acquired for study purposes but as a clinical routine, and the small number of cases limit the value of the statistical analysis and the strength of the conclusions. We introduced a potential selection bias by enrolling only patients, in whom the disease had been confirmed histologically via surgical lung biopsy. As only $16 \%$ of all patients with LC had histologically reported $\mathrm{RB}$, one may speculate that $\mathrm{RB}$ was not always worth mentioning, resulting in underreporting. A further limitation is the general difficulty that associations may not be interpreted as causal relationships. The strongest causal factor behind both RB and the associated diseases was certainly cigarette smoking.

\section{Conclusion}

$\mathrm{RB}$ is caused by cigarette smoke and is related to lung emphysema, LC, PLCH, SP, and ILD. The diagnosis of RB-ILD is essentially clinical/radiological, requiring the presence of a variable combination of symptoms, clinical signs, and abnormal findings on chest radiography or HR-CT. Since RB and RB-ILD are strongly associated with LC, incidental findings should induce close followup observation and a very strong recommendation to stop smoking.

\section{Acknowledgments}

The authors are indebted to the members of ArGe-Lunge-Steiermark - the Association of the Styrian pulmonologists - for supporting us with patient data. The authors would also like to thank Dr. Alexander Avian and Mag. Gerold Schwantzer, both Institute for Medical Informatics, Statistics and Documentation of the Medical University Graz, for their statistical support.

\section{Financial Disclosure and Conflicts of Interest}

The authors have no conflicts of interest to disclose.

\section{References}

1 Niewoehner DE, Kleinerman J, Rice DB: Pathologic changes in the peripheral airways of young cigarette smokers. N Engl J Med 1974;291:755-758

2 Colby TV: Bronchiolitis. Pathologic considerations. Am J Clin Pathol 1998;109:101-109.

-3 Katzenstein AL, Myers JL: Idiopathic pulmonary fibrosis: clinical relevance of pathologic classification. Am J Respir Crit Care Med 1998;157(4 Pt 1):1301-1315.

-4 Seely JE, Zuskin E, Bouhuys A: Cigarette smoking: objective evidence for lung damage in teen-agers. Science 1971;172:741-743.
-5 Myers JL, Veal CF Jr, Shin MS, Katzenstein AL: Respiratory bronchiolitis causing interstitial lung disease. A clinicopathologic study of six cases. Am Rev Respir Dis 1987;135:880-884.

-6 Yousem SA, Colby TV, Gaensler EA: Respiratory bronchiolitis-associated interstitial lung disease and its relationship to desquamative interstitial pneumonia. Mayo Clin Proc 1989; 64:1373-1380.

7 Moon J, du Bois RM, Colby TV, Hansell DM, Nicholson AG: Clinical significance of respiratory bronchiolitis on open lung biopsy and its relationship to smoking related interstitial lung disease. Thorax 1999;54:1009-1014.
8 Aubry MC, Wright JL, Myers JL: The pathology of smoking-related lung diseases. Clin Chest Med 2000;21:11-35, vii.

-9 Fraig M, Shreesha U, Savici D, Katzenstein AL: Respiratory bronchiolitis: a clinicopathologic study in current smokers, ex-smokers, and never-smokers. Am J Surg Pathol 2002; 26:647-653.

10 Myers JL, Katzenstein AL: Beyond a consensus classification for idiopathic interstitial pneumonias: progress and controversies. Histopathology 2009;54:90.

Scheidl/Kusej/Flick/Stacher/Matzi/ Kovacs/Popper/Costabel/Olschewski 
$\$ 11$ Wright JL, Tazelaar HD, Churg A: Fibrosis with emphysema. Histopathology 2011;58: 517-24.

12 Remy-Jardin M, Remy J, Gosselin B, Becette V, Edme JL: Lung parenchymal changes secondary to cigarette smoking: pathologic-CT correlations. Radiology 1993;186:643-51.

13 Holt RM, Schmidt RA, Godwin JD, Raghu G: High resolution CT in respiratory bronchiolitis-associated interstitial lung disease. J Comput Assist Tomogr 1993;17:46-50.

14 Park JS, Brown KK, Tuder RM, Hale VA, King Jr TE, Lynch DA: Respiratory bronchiolitisassociated interstitial lung disease: radiologic features with clinical and pathologic correlation. J Comput Assist Tomogr 2002;26:13-20.

-15 Wells AU, Nicholson AG, Hansell DM, du Bois RM: Respiratory bronchiolitis-associated interstitial lung disease. Semin Respir Crit Care Med 2003;24:585-594.

16 Vassallo R, Jensen EA, Colby TV, Ryu JH, Douglas WW, Hartman TE, Limper AH: The overlap between respiratory bronchiolitis and desquamative interstitial pneumonia in pulmonary Langerhans cell histiocytosis. Chest 2003;1199-1205.

17 Caminati A, Harari S: Smoking-related interstitial pneumonias and pulmonary Langerhans cell histiocytosis. Proc Am Thorac Soc 2006;3:299-306.
18 Cottin V, Streichenberger N, Gamondes JP, Thévenet F, Loire R, Cordier JF: Respiratory bronchiolitis in smokers with spontanous pneumothorax. Eur Respir J 1998;12:702704.

19 Sverzellati N, Guerci L, Randi G, Calabrò E, La Vecchia C, Marchianò A, Pesci A, Zompatori $\mathrm{M}$, Pastorino $\mathrm{U}$ : Interstitial lung diseases in a lung cancer screening trial. Eur Respir J 2011;38:392-400.

20 Heynemann LE, Ward S, Lynch DA, RemyJardin M, Johkoh T, Müller NL: Respiratory bronchiolitis, respiratory bronchiolitis-associated interstitial lung disease, and desquamative interstitial pneumonia: different entities or part of the spectrum of the same disease process? Am J Roentgenol 1999;173:16171622.

21 Portnoy J, Veraldi KL, Schwarz MI, Cool CD, Curran-Everett D, Cherniack RM, King TE Jr, Brown KK: Respiratory bronchiolitis-interstitial lung disease: long-term outcome. Chest 2007;131:664-671.

-22 Scheidl S, Kovacs G, Stacher E, Popper H, Olschewski H: A 55-year-old craftsman with dyspnea and clubbing: a case report. Cases J 2009;2:8579.

23 Minghini A, Trogdon SD: Recurrent spontaneous pneumothorax in pulmonary histiocytosis X. Am Surg 1998;64:1040-1042.
24 Adesina AM, Vallyathan V, McQuillen EN: Bronchiolar inflammation and fibrosis associated with smoking: a morphologic crosssection population analysis. Am Rev Respir Dis 1991;143:144-149.

25 Agius RM, Rutman A, Knight RK, Cole PJ: Human pulmonary alveolar macrophages with smokers' inclusions: their relation to the cessation of cigarette smoking. Br J Ex Pathol 1986;67:407-413.

26 Wright JL, Lawson LM, Pare PD, Wiggs BJ, Kennedy S, Hogg JC: Morphology of peripheral airways in current smokers and ex-smokers. Am Rev Respir Dis 1983;127:474-477.

27 Bogin RM, Niccoli SA, Waldron JA, Cherniack RM, Thurlbeck WM, Flint A, Colby TV, Schwarz MI, King TE: Respiratory bronchiolitis: clinical presentation and bronchoalveolar lavage findings. Chest 1988;94:21.

28 Königshoff M: Lung cancer in pulmonary fibrosis: tales of epithelial cell plasticity. Respiration 2011;81:353-358.

29 Yamada Y, Terada J, Tatsumi K, Kono C, Tanno M, Takemura T, Yamaguchi T: Respiratory bronchiolitis and lung carcinoma. Respir Investig 2013;51:184-90.

-30 Sadikot RT, Johnson J, Loyd JE, Christman JW: Respiratory bronchiolitis associated with severe dyspnea, exertional hypoxemia, and clubbing. Chest 2000;117:282-285. 